\title{
ALGUNS ASPECTOS DA ESCOLARIZAÇÃO DE CRIANÇAS NAS ÚLTIMAS DECADAS
}

\author{
Stella Maria Poletti Simionato-Tozo* \\ Zélia Maria Mendes Biasoli-Alves**
}

\section{RESUMO}

A Escola na atualidade vem sendo muito discutida. E frequentemente falado que ela passa por um conjunto de alterações e que são grandes as dificuldades que enfrenta. Os objetivos desse estudo estão voltados para a análise de dados que descrevem o procèsso de escolarização de crianças nas décadas de 60/70 e na atualidade, visando traçar comparações e identificar possíveis variáveis associadas às mudanças observadas.

\section{INTRODUÇÃO}

O processo de escolarização vem sendo muito discutido ultimamente, e sem dúvida que o assunto interessa, de perto, aos educadores, não só enquanto análise das alterações mais recentes, mas sobretudo visando estabelecer projetos e programas adequados ao futuro.

A escola, enquanto instituição social, tem como função possibilitar o acesso das crianças à cultura letrada, reafirmando os valores, habilidades e conhecimentos que a sociedade considera importantes (Kleiman, 1993).

Desta maneira, Fusari (1990) ressalta que as relações entre a educação escolar e a sociedade, em diferentes momentos históricos, foram determinando o papel que a educação deveria cumprir, de acordo com os interesses sócioeconômico-políticos dominantes em diferentes momentos. A educação escolar como não-neutra e com seu espaço de reprodução das desigualdades sociais, na sociedade capitalista, é um fato bastante aceito entre os educadores.

É ressaltado então que a educação sofre alterações segundo o momento sócio-histórico-social. Segundo Penin (1990), nas últimas décadas, o sistema público de ensino foi marcado por três fenômenos que determinaram fortemente sua atual configuração. $O$ primeiro foi o processo de burocratização, devido à penetração da tendência tecnicista da educação em nosso país, que provocou fragmentação na estrutura e funcionamento do ensino em todos os níveis. Segundo, o processo de democratização da escola resultou em uma súbita

* Mestre em Educação Especial - PPGEES- UFSCar

** Prof. Associada do Depto de Psicologia e Educação FFCL RP USP

Paidéia, FFCLRP-USP, Rib. Preto, Fev/Ago 96. 
ampliação da rede de ensino e no aumento da heterogeneidade da clientela escolar devido ao acesso à escola de crianças provindas das camadas populares. E o terceiro fenômeno relaciona-se ao processo de pauperização da profissão docente, que levou profissionais, muitas vezes malformados, a assumirem jornadas de trabalho duplas ou triplas, interferindo na qualidade da atuação profissional.

Esta autora aponta que a extensão da escolarização fundamental a amplas parcelas da população foi o processo mais significativo, bem como a saída de boa parte dos alunos de camadas médias das escolas públicas para as particulares, principalmente a partir dos anos 70 .

A situação da educação no Brasil tem sido bastante discutida e muitas queixas são feitas, tanto entre os profissionais da educação, quanto entre os usuários de seus serviços. A responsabilidade é atribuída a diversos fatores: ao sistema administrativo, à burocracia, à condição dos alunos, à figura do professor, à universidade, etc ( Cardoso, 1990).

No entanto, em meio a tantas discussões quanto à educação escolar, ela é muito valorizada pelas famílias, ainda que venha se alterando rapidamente nas últimas décadas.

O processo de escolarização sofre transformações para responder às mudanças impostas pela sociedade, principalmente pela família. $\mathrm{O}$ rápido aumento do número de mães que ingressam no mercado de trabalho acarreta a transformação no cuidado diário de crianças pequenas, havendo a expansão de instituições públicas e privadas com este objetivo (Sommer \& Langsted, 1994).

Trabalhos nacionais como o de Di Ciommo (1986) e Dias-da-Silva (1986) vêm confirmar este quadro descrito acima: "a escolarização precoce dos filhos se situa neste contexto: na medida em que eles não têm a presença da mãe em tempo integral, pouca possibilidade de contato com outras crianças em casa, espaço restrito, tanto fora quanto dentro dela, a escolinha aparece como alternativa possível e mais adequada para preencher suas necessidades" (Diasda-Silva, 1986,p 226 ).

Pode-se pois partir do fato de que muitas transformações já ocorreram, e num espaço relativamente curto de tempo, o que faz emergirem algumas questões voltadas para a indagação de como as pessoas os estão percebendo, em especial quando podem estabelecer comparações entre o que vivenciaram e o que está acontecendo com seus filhos.

Este trabalho foi pois estruturado visando descrever qual a visão que adultos possuem de sua escolarização na fase restrita à infância nas décadas de 60 e 70, e como vêm se processando a de seus filhos, durante a pré-escola e séries iniciais do $1^{\circ} \mathrm{grau}$.

\section{MÉTODO}

\section{Descrição da Amostra}

Foram selecionados 15 casais de camadas médias, de uma cidade 
grande do interior paulista, que possuiam uma prole de 2 ou 3 filhos, sendo o primogênito uma criança entre 6 a 10 anos de idade. Suas características são apresentadas no Quadro 1.

Quadro 1 - Caracterização das famílias segundo a idade, grau de instrução e a atuação profissional dos pais e mães, idade e sexo dos filhos.

\begin{tabular}{|c|c|c|c|c|}
\hline Pai e Mãe & Idade & $\begin{array}{l}\text { Grau de } \\
\text { Instruçãá }\end{array}$ & $\begin{array}{c}\text { Atividade } \\
\text { Profissional }\end{array}$ & $\begin{array}{c}\text { Idade e Sexo } \\
\text { dos Filhos }\end{array}$ \\
\hline $\begin{array}{l}1 \\
\text { M } 1\end{array}$ & $\begin{array}{l}42 \\
34 \\
\end{array}$ & $\begin{array}{l}\text { Sec. (Sup. Inc) } \\
\text { Universitário }\end{array}$ & $\begin{array}{l}\text { Comerciante } \\
\text { Bancária }\end{array}$ & $\begin{array}{l}10 \text { a M; } 9 \text { a M; } \\
7 \text { a M }\end{array}$ \\
\hline $\begin{array}{l}\mathrm{P} 2 \\
\mathrm{M} 2\end{array}$ & $\begin{array}{l}32 \\
27 \\
\end{array}$ & $\begin{array}{l}\text { Sec.(Sup. Inc) } \\
\text { Sec. (Sup. Inc) }\end{array}$ & $\begin{array}{l}\text { Vendedor } \\
\text { Do Lar }\end{array}$ & $\begin{array}{l}7 \text { a M; } 5 \text { a F; } \\
3 \text { a F }\end{array}$ \\
\hline $\begin{array}{l}\text { P3 } \\
\text { M3 }\end{array}$ & $\begin{array}{l}33 \\
32 \\
\end{array}$ & $\begin{array}{l}\text { Universitário } \\
\text { Secundário }\end{array}$ & $\begin{array}{l}\text { Comerciante } \\
\text { Do Lar }\end{array}$ & $8 \mathrm{aM} ; 6$ aF \\
\hline $\begin{array}{l}\mathrm{P} 4 \\
\mathrm{M} 4\end{array}$ & $\begin{array}{l}35 \\
36 \\
\end{array}$ & $\begin{array}{l}\text { Universitário } \\
\text { Universitário }\end{array}$ & $\begin{array}{l}\text { Comerciante } \\
\text { Do Lar }\end{array}$ & 10 a M; $7 \mathrm{M}$ \\
\hline $\begin{array}{l}\text { P } 5 \\
\text { M5 }\end{array}$ & $\begin{array}{l}33 \\
27 \\
\end{array}$ & $\begin{array}{l}\text { Universitário } \\
\text { Secundário }\end{array}$ & $\begin{array}{l}\text { Comerciante } \\
\text { Do Lar }\end{array}$ & $\begin{array}{l}8 \text { a M; } 4 \text { a M; } \\
2 \text { a F }\end{array}$ \\
\hline $\begin{array}{l}\text { P6 } \\
\text { M6 }\end{array}$ & $\begin{array}{l}39 \\
37 \\
\end{array}$ & $\begin{array}{l}\text { Univ. (Pós-Gr) } \\
\text { Universitário } \\
\end{array}$ & $\begin{array}{l}\text { Bancário } \\
\text { Bancária }\end{array}$ & $8 \mathrm{aM} ; 6 \mathrm{aM}$ \\
\hline $\begin{array}{l}\text { P7 } \\
\text { M7 }\end{array}$ & $\begin{array}{l}36 \\
36 \\
\end{array}$ & $\begin{array}{l}\text { Universitário } \\
\text { Universitário }\end{array}$ & $\begin{array}{l}\text { Comerciante } \\
\text { Comerciante }\end{array}$ & $9 \mathrm{aF} ; 5 \mathrm{aF}$ \\
\hline $\begin{array}{l}\text { P } 8 \\
\text { M } 8 \\
\end{array}$ & $\begin{array}{l}33 \\
25 \\
\end{array}$ & $\begin{array}{l}\text { Universitário } \\
\text { Secundário }\end{array}$ & $\begin{array}{l}\text { Comerciante } \\
\text { Comerciante }\end{array}$ & $\begin{array}{l}7 \text { a M } \\
4 \text { a M }\end{array}$ \\
\hline $\begin{array}{l}\text { P9 } \\
\text { M9 }\end{array}$ & $\begin{array}{l}35 \\
34 \\
\end{array}$ & $\begin{array}{l}\text { Universitário } \\
\text { Universitário }\end{array}$ & $\begin{array}{l}\text { Engenheiro } \\
\text { Tradut/Interprete }\end{array}$ & $8 \mathrm{aF} ; 4 \mathrm{aM}$ \\
\hline $\begin{array}{l}\text { P } 10 \\
\text { M } 10 \\
\end{array}$ & $\begin{array}{l}36 \\
29 \\
\end{array}$ & $\begin{array}{l}\text { Universitário } \\
\text { Ginasial }\end{array}$ & $\begin{array}{l}\text { Func. Público } \\
\text { Do Lar }\end{array}$ & $\begin{array}{l}8 \mathrm{aM} \\
4 \text { a M } \\
\end{array}$ \\
\hline $\begin{array}{l}\text { P } 11 \\
\text { M 11 }\end{array}$ & $\begin{array}{l}45 \\
43 \\
\end{array}$ & $\begin{array}{l}\text { Universitário } \\
\text { Universitário } \\
\end{array}$ & $\begin{array}{l}\text { Instr. Auto-Escola } \\
\text { Func. Pública }\end{array}$ & $\begin{array}{l}10 \mathrm{aM} ; \\
8 \mathrm{aF}\end{array}$ \\
\hline $\begin{array}{l}\mathrm{P} 12 \\
\mathrm{M} 12\end{array}$ & $\begin{array}{l}38 \\
34 \\
\end{array}$ & $\begin{array}{l}\text { Universitário } \\
\text { Universitário }\end{array}$ & $\begin{array}{l}\text { Func. Público } \\
\text { Do Lar }\end{array}$ & $\begin{array}{l}7 \mathrm{aM} ; 3 \text { aF } \\
1 \mathrm{aM}\end{array}$ \\
\hline $\begin{array}{l}\text { P } 13 \\
\text { M } 13 \\
\end{array}$ & $\begin{array}{l}37 \\
32 \\
\end{array}$ & $\begin{array}{l}\text { Univ. (Pós-Gr) } \\
\text { Universitário }\end{array}$ & $\begin{array}{l}\text { Dentista/ Prof. Univ. } \\
\text { Comerciante }\end{array}$ & 6 aF; 3aM \\
\hline $\begin{array}{l}\text { P } 14 \\
\text { M } 14 \\
\end{array}$ & $\begin{array}{l}39 \\
37 \\
\end{array}$ & $\begin{array}{l}\text { Universitário } \\
\text { Sec. (Sup. Inc) }\end{array}$ & $\begin{array}{l}\text { Func. Público } \\
\text { Func. Pública }\end{array}$ & $\begin{array}{l}9 \text { a M } \\
7 \text { a M }\end{array}$ \\
\hline $\begin{array}{l}\text { P } 15 \\
\text { M } 15\end{array}$ & $\begin{array}{l}33 \\
31 \\
\end{array}$ & $\begin{array}{l}\text { Universitário } \\
\text { Univ. (Pós-Gr) }\end{array}$ & $\begin{array}{l}\text { Admin/ Prof. Univ. } \\
\text { Dentista/ Prof. Univ. }\end{array}$ & $6 \mathrm{aM} ; 4 \mathrm{aF}$ \\
\hline
\end{tabular}

Paidéia, FFCLRP-USP, Rib. Preto, Fev/Ago 96. 
Pode-se observar:

1) Pais: idades variando dos 32 aos 45 anos; $87 \%$ com nível universitário; profissões variadas,

2) Mães: idades variando dos 25 aos 43 anos; $60 \%$ com nível universitário e $33 \%$ secundário; $60 \%$ exercendo atividades fora do lar,

3) Crianças: ao todo são 34 , sendo $65 \%$ do sexo masculino e $35 \%$ do feminino e, quanto à idade, $65 \%$ possuem de 6 aos 10 anos e $35 \%$ de 1 a 5 anos.

\section{Procedimento*}

A pesquisadora entrou em contato com possíveis informantes de seu círculo de conhecimento e colocou-as a par dos objetivos de seu trabalho e das características dos sujeitos, pedindo-lhes que indicassem pessoas que poderiam se enquadrar neste estudo. A partir destas indicações, as famílias selecionadas foram contactadas pela pesquisadora que, de início, expôs o objetivo geral da pesquisa, explicando para os pais a forma de obtenção dos dados (entrevista) e verificando a disponibilidade deles em participar. Obtida a anuência, foram marcadas as entrevistas com os pais e definido o local de sua preferência para a realização das mesmas. No momento da entrevista, a pesquisadora-entrevistadora explicou aos pais a necessidade de gravação como forma de registro de dados mais fidedigna, realçando o caráter confidencial da gravação.

As entrevistas aconteceram, na sua maioria, na residência dos pais. Foram feitas individualmente, no mesmo dia ou não, e gravadas. $O$ tempo de duração de cada uma delas variou de uma a duas horas e meia.

Para este trabalho, foram selecionadas as questões que integravam o tópico referente à Escola, investigando: a idade de ingresso da criança na escola; $o$ incentivo ao estudo por parte da família; $o$ auxílio dos pais quanto às tarefas escolares; o grau acadêmico atingido e os motivos que levaram os pais e mães a alcançá-lo; uma avaliação geral do processo de escolarização pelo qual cada sujeito passou.; o papel esperado pelos pais que a escola de seus filhos cumpra

"Este estudo é parte da dissertação de mestrado de SIMIONATO-TOZO (1996), intitulada “ $A$ infância em gerações diferentes: o cotidiano e o lúdico", PPGEEs/ UFSCar. Esta pesquisa traz dados sobre alguns aspectos da vida familiar e da infância brasileira, especialmente sobre o lúdico, durante as últimas décadas. Os participantes foram entrevistados, pai e mãe individualmente, segundo um roteiro de entrevistas semi-estruturado que foi elaborado especialmente para este estudo, abrangendo 3 grandes áreas: 1) a infância dos pais; 2) a infância dos filhos (ambas com tópicos sobre brincadeiras, brinquedos, escola e vida em família); 3) avaliações e comparaçð̃es sobre a infância das duas geraçð̃es. As questð̃es que compõem cada área ora solicitam descrições, ora julgamentos. Os resultados descrevem cada uma das diferentes gerações e trazem comparaçð̃es entre elas. 
e a ocorrência e a importância de atividades extra-escolares para cada uma das gerações. O Anexo I traz estas questões na íntegra.

\section{RESULTADOS}

Os dados foram analisados de acordo com suas características, buscando compor uma descrição quantitativa de certos aspectos das escolarizações, complementados por outra descrição qualitativa*

\section{1) $O$ ingresso da criança na escola.}

A tabela abaixo traz a idade de ingresso da criança na escola, ou em ambiente coletivo como creches e berçários para aquelas cuja entrada ocorreu com menor idade (meses até 2 anos), na atualidade.

TABELA 1: Idade de ingresso da criança na escola ou ambiente coletivo, para os pais, as mães e seus filhos.

\begin{tabular}{|c|c|c|c|c|c|}
\hline \multicolumn{6}{|c|}{ IDADE DE INGRESSO NA ESCOLA OU EM AMBIENTE COLETIVO } \\
\hline Familia & Pai & Mãe & 10 Filho & $2^{2}$ Filho & $3^{2}$ Filho \\
\hline 1 & 7 & 7 & 3 & 4 & 6 \\
\hline 2 & 6 & 8 & 4 & 2 & 1 \\
\hline 3 & 7 & 6 & 5 & 5 & - \\
\hline 4 & 6 & não obtido & 4 a 5 & 4 a 5 & - \\
\hline 5 & 6 & 6 & 2 anos e $6 \mathrm{~m}$ & 2 anos e $4 \mathrm{~m}$ & não frequenta \\
\hline 6 & 7 & 7 & 5 & 3 & - \\
\hline 7 & 7 & 7 & 4 a 5 & 4 a 5 & - \\
\hline 8 & 6 & 5 & 3 anos e $6 \mathrm{~m}$ & 2 & - \\
\hline 9 & 6 & 7 & 1 & 2 & - \\
\hline 10 & 7 & 7 & 6 & não freqüenta & - \\
\hline 11 & 11 & 7 & 2 & 3 & - \\
\hline 12 & 7 & 7 & 3 & não freqüenta & não freqüenta \\
\hline 13 & 7 & 6 & $3 \mathrm{a} \mathrm{e} 6 \mathrm{~m}$ & $2 \mathrm{a} \mathrm{e} 6 \mathrm{~m}$ & - \\
\hline 14 & 8 & 6 & 3 & 4 & - \\
\hline 15 & 5 & 6 & 3 meses & 2 anos & - \\
\hline
\end{tabular}

* $\mathrm{O}$ uso de um roteiro semi-estruturado, com entrevistas gravadas e transcritas na íntegra, que dava ênfase à fala dos sujeitos e aprofundava em investigações sobre os temas de interesse, tornou possível a análise qualitativa dos dados, utilizando-se para tal a proposta de BiasoliAlves e Dias-da-Silva (1992). 
Pela Tabela 1 observa-se que o processo de escolarização dos pais e das mães inicia-se com a entrada na $1^{\mathrm{a}}$ série do $1^{\circ}$ grau para a maioria deles aos 6 e 7 anos, existindo algumas exceções, tanto para mais, como a de um pai que entrou um pouco mais velho, pois morava em fazenda e a preocupação com a escolarização não era muito grande; quanto para menos, referente àqueles que freqüentaram o pré-primário, mas que ressaltam que não aprendiam a ler, nem a escrever: " não sabia nada".

$\mathrm{Na}$ atualidade, entretanto, a maior tendência é para a entrada na escola entre os 3 e 6 anos (56\%), havendo um número relativamente grande de crianças (32\%) que aos 2 anos de idade já estava freqüentando algum ambiente coletivo, contra apenas $12 \%$ que até os 4 anos permaneciam só em casa.

Os motivos atribuídos pelas mães e pelos pais para a entrada da criança no ambiente escolar ou coletivo, antes do $1^{\circ}$ grau, estão listados abaixo:

\begin{tabular}{l}
\hline Motivos para o ingresso na escola ou ambiente coletivo \\
\hline problemas com a empregada que cuidaria da criança enquanto a må̃e trabalhava \\
(falta de confiança, excesso de falta no trabalho) \\
\hline para os filhos conviverem com crianças e adultos \\
\hline porque a mãe trabalhava fora de casa \\
\hline para as crianças desenvolverem habilidades cognitivas / disciplina \\
\hline
\end{tabular}

Algumas frases ilustrativas são: "eu percebi que elas tinham necessidade de conviver mais com outras crianças"; "vai aprender a desenhar, a pintar, a escrever, a aprender alguma coisa, né ?"

Nestas famílias a decisão de colocar a criança na escola é tomada pelas mães, e ainda que a maioria delas tenha como ideal que isto ocorra por volta dos 4 anos de idade, o que se observa é que bem mais cedo elas já estão no ambiente coletivo. Também não faltam aquelas mães que fazem do período da criança na escola o "seu tempo": "são 4 horas, 4 horas que eles vão se relacionar e 4 horas que as mães têm um pouco de sossego, pra se cuidar ou pra ficar quieta".

\section{2) As atividades extra-escolares.}

A ocorrência de atividades extra-escolares na infância dos pais e mães pode ser vista na tabela abaixo. 
TABELA 2:. Freqüência de ocorrência de cursos extra-escolares na infância dos pais e mães.

\begin{tabular}{|c|c|c|}
\hline Tipo De Cursos & Pais & Mães \\
\hline Música ( Piano, Violão, Órgão) & 4 & 4 \\
\hline $\begin{array}{c}\text { Esportes ( Natação, Judô, Voley, } \\
\text { Basquete, Tênis, Ginástica Olímpica) }\end{array}$ & 6 & 5 \\
\hline Dança (Balé) & $-\cdot$ & 4 \\
\hline Inglês & 1 & 3 \\
\hline Corte e Costura & - & 2 \\
\hline
\end{tabular}

Parte da amostra (53\% dos Pais e $47 \%$ das Mães) teve a oportunidade de participar de atividades físicas (natação, judô), aprendizado de música (piano, violão, orgão) e dança para as meninas, e na adolescência curso de línguas (inglês) para ambos os sexos e o curso de corte e costura para as mães.

O que fica claro nas entrevistas é que tais cursos acabavam não tendo continuidade, iniciavam-se pelo interesse da criança e duravam enquanto este permanecesse: "sempre eu tive a oportunidade de fazer o que quisesse, isso aí nunca teve problema, sabe, de fazer um curso, nunca apresentou problema financeiro, não, eu mesmo é que não dava prosseguimento aos cursos".

$O$ restante da amostra da $1^{\text {a }}$ geração, que não fêz cursos, declara que o motivo foi a maneira de pensar de sua família de origem: "Esse tipo de preocupação não existia na família. A preocupação era você estudar, sua escola e acabou".

Com a $2^{a}$ geração, quase todas as crianças ou já fizeram alguma atividade, , ou estão fazendo ou ainda não fazem, mas as mães pretendem colocálas, como mostra o quadro a seguir:

Paidéia, FFCLRP-USP, Rib. Preto, Fev/Ago 96. 
Quadro 2. Cursos para as crianças: realizados anteriormente, na atualidade e pretendido para o futuro pelos pais e mães.

\begin{tabular}{|c|c|c|c|}
\hline Familia & $\begin{array}{c}\text { Curso Realizado } \\
\text { Anteriormente }\end{array}$ & $\begin{array}{c}\text { Curso Realizado } \\
\text { Atualmente }\end{array}$ & $\begin{array}{c}\text { Curso Pretendido } \\
\text { Para o Futuro }\end{array}$ \\
\hline 1 & Natação, Violåo & - & - \\
\hline 2 & - & Natação & Judô, Violăo, Inglês \\
\hline 3 & - & Natação & Violâo, Inglês \\
\hline 4 & Judô & - & Inglês \\
\hline 5 & - & Basquete & - \\
\hline 6 & - & Natação & $\begin{array}{c}\text { Inglês, Karatê, Judô } \\
\text { ou Capoeira }\end{array}$ \\
\hline 7 & - & Piano & Teatro, Inglês \\
\hline 8 & - & Natação & Inglês, Computação \\
\hline 9 & Balé, Natação & - & Esporte \\
\hline 10 & Nataçăo & - & Judô \\
\hline 11 & - & - & Esporte \\
\hline 12 & Natação & - & Esporte, Inglês \\
\hline 13 & - & Balé, Tênis & Natação \\
\hline 14 & Natação & - & Judô \\
\hline 15 & - & Natação & - \\
\hline
\end{tabular}

Ao se fazer uma análise dos tipos de cursos citados, independente da época (passado, presente ou pretendido para o futuro), nota-se que os ligados a esportes são os mais freqüentes (58\%), depois vem o aprendizado de línguas (19\%), seguido de instrumentos musicais $(11 \%)$ e dança $(6 \%)$ e teatro e computação com 3\% cada um.

Tanto as mães quanto os pais consideram estes cursos importantes para o desenvolvimento das crianças, porque estimulam habilidades intelectuais, físicas e sociais, embora salientem que este tipo de atividade deva ocorrer "desde que seja da vontade deles (filhos)". Já o aprendizado da língua inglesa é realçado, pois "ajuda muito na vida adulta", sendo "um curso acho que imprescindivel hoje pra qualquer brasileiro, né ? "

Alguns fatores são citados como impeditivos da participação pela criança nessas atividades, tais como a dificuldade de conciliar horários de levar/ 
buscar e o trabalho da mãe, pois "tudo fica dificil, que tudo a gente tem que levar, não tem o negócio de dizer 'eles vão'"; e o gasto financeiro que requerem: "parou por falta de dinheiro mesmo".

Mas é como se a educação ficasse prejudicada porque as oportunidades não são oferecidas à criança na medida do desejo dos pais.

\section{3) A participação da família no processo de escolarização.}

Ao longo do tempo as famílias parecem vir numa valorização crescente "do estudo" para os filhos, tanto assim que a maioria dos pais e mães relata que havia incentivo "educação era prioridade" ou "sempre incentivavam, sempre quando vinha alguma coisa boa elogiavam, sempre quando tinha algum ponto fraco, procuravam me incentivar e corrigir, pra eu melhorar." As vezes isto acontecia sob a forma de cobranças ou imposições "era uma coisa obrigatória, era uma coisa imposta, você tinha que estudar, você tinha que aprender a ler"; "Meu pai cobrava, queria saber como estava e não fez mais do que a obrigação quando passou de ano, não era premiado também quando passou de ano, você era repreendido se estava pisando na bola". Outras vezes o que acontecia era mostrar os problemas que a falta de estudo acarretaria: "estuda porquê senão você vai ser bóia-fria". Mas, ainda se encontra o pouco estímulo ao estudo por ser mulher.

Por outro lado, para as famílias em que o trabalho dos filhos era essencial como auxílio à subsistência, as crianças (meninos ou meninas) chegaram a interromper os estudos durante um tempo "eles não tinham condição de me manter sem depender do meu trabalho, então eles dependiam do meu trabalho, ai ficava aquela coisa difícil".

Além do incentivo, parte dos pais e mães puderam contar com o auxílio dos adultos para a realização das tarefas acadêmicas: "mas quem tinha mais tempo de ensinar a gente, de ficar ali do lado dando força, era a mãe, o pai não tinha muito tempo não, era mais desligado, tinha outros afazeres fora de casa".

Enquanto para algumas crianças os pais eram bastante próximos e capazes de ajudar "Minha mãe me ajudava, pela própria formação dela, era professora primária, né, ajudava um pouco e tinha horário fixo."; "eles davam uma olhada, tomavam a lição, tomavam a lição mesmo, e acompanhavam o boletim, acompanhavam o caderno."; para outros este auxílio encontrava limitações no nível de instrução dos pais, que aparecia como um fator determinante: "o próprio grau de instrução que meus pais tiveram, meu pai

Paidéia, FFCLRP-USP, Rib. Preto, Fev/Ago 96. 
teve até o $2^{\circ}$ ano primário só, minha mãe até o $3^{\circ}$, eles não se sentiam, acho, muito à vontade pra orientar, talvez por não saber até realmente do que se tratava aquela matéria."; "porque a minha mãe, a leitura dela era muito pouca, certo ? Meu pai também. Então a gente tinha que se virar sozinho mesmo".

$\mathrm{O}$ que o relato de pais e mães evidencia quanto às gerações mais novas é que eles incentivam as crianças para o estudo, e o auxílio nas tarefas escolares é uma constante para toda a amostra, e embora a participação dos pais (homens) seja maior que na geração anterior: "ajudamos na pesquisa de trabalhos, ajudamos na confecção dos trabalhos escolares, né, nas lições, damos ditado, damos frases, corrigimos. Orientamos, corrigimos professores (risos)", esta ainda é uma atividade essencialmente da mãe, e eles mesmos ressaltam: "ela é a segunda professora dele".

Entretanto, quando se focaliza o comportamento das crianças, há muita diversidade; de um lado há as que não dão trabalho "ela já sabe que ela tem que cumprir a parte dela da escola", e de outro lado há aquelas que "a gente tem que ficar bem em cima".

Também existem as análises críticas dos pais quanto ao que a Escola propõe "uma coisinha um pouquinho mais elaborada pra fazer em casa".

\section{4) Avaliação da vida escolar da $1^{\mathfrak{a}}$ geração.}

O processo de escolarização para a maioria foi longo, iniciando-se na $1^{\text {a }}$ série do primeiro grau e encerrando-se no curso superior (ou de pós-graduação), como pode ser observado no Quadro 1, existindo a percepção de que o curso universitário é importante. A tendência para alcançar este grau na amostra é justificada por relacioná-lo a um nível de vida melhor, em termos de remuneração e de futuro profissional: "quanto mais estudasse, mais chance tinha..."; "até por questão de 'status', né, até por questão de 'oh, você vai pegar uma chefia, se você tivesse um nível superior"; "O salário era muito baixo, tal... e... e eu me dediquei a fazer a faculdade".

Entretanto boa parte dessa amostra chega a cursar uma universidade sem se profissionalizar através do título obtido que fica mais como um elemento facilitador de um bom emprego ou de mudança de nível nele, o que justifica o abandono da graduação quando as perspectivas de alteração são descartadas: "não ia virar nada e tal"... "até onde eu fui, eu tava me virando e achava que não havia necessidade. Parei por isso."; e "eu tava fazendo não por escolha, mas porque era o que dava pra fazer...". 
Por outro lado, as obrigações frente ao nascimento de filhos ou mesmo o casamento ainda aparecem como fatores determinantes da interrupção dos estudos ou da não profissionalização de muitas mães desta amostra.

Não resta dúvida de que os pais e mães avaliam a escola com importante em suas vidas, existindo grande valorização do estudo e do conhecimento adquirido nas diferentes fases da escolarização, trazendo sempre algum benefício que é percebido por eles na vida atual.: "abre a mente da gente, a gente depois precisa cair na vida mesmo, defender a vida, então você fica bem preparado"; "Aquilo que eu sou hoje, eu ..., o meu ganha-pão, a minha vida hoje, eu devo a escola"; "acho que a escola é tudo mesmo, a gente tem que a vida inteira estudar; é onde a gente conhece as pessoas, onde a gente tem os amigos, onde a gente aprende, onde a gente ensina ...".

\section{5) A escolarização dos filhos na atualidade.}

E como os pais vêem a escolarização de seus filhos ?Quê expectativas têm ? O que esperam atingir ? Quê tarefas estão se atribuindo ? Há muitas diferenças ou apenas semelhanças nas percepções de pais e mães?

Das 34 crianças que compõem esta amostra, $88 \%$ freqüenta a escola, sendo que destas $77 \%$ estuda em escolas particulares, escolhidas pelos pais e mães, contra 23\% que estão em escolas municipais ou estaduais.

Observa-se que a preocupação da maioria das mães é com o conhecimento acadêmico que deve ser passado às crianças. Aparecem pontos de vista mais isolados sobre a escola como: a) a escola das crianças deve ser escolhida tendo em vista o estilo de vida da família " eu não poderia por ela numa escola em que é aquele método rígido, tipo militar, se eu não vivo desse jeito dentro de casa"; b) a sobrecarga de tarefas com muito conteúdo acadêmico, "o que acaba com a infância" das crianças; c) a transferência de responsabilidade sobre assuntos escolares para os pais: " a única coisa que ela (professora) falava 'olha, tomem leitura, tomem tabuada dos seus filhos, tomem isso, tomem aquilo', eu acho que não é por aí"; d) a socialização da criança através da Escola "tinha que entrar às 8 (horas da manhã) e sair as 6 (horas da tarde)", onde haveria aulas de estudos em si (...), aula do lanche, ensinar a criança a comer, ensinar a criança a andar, aula do banho, aula da higiene, acho que deveria ter todos os tipos de aula".

Para os pais o papel da escola seria o de "formação dessas crianças (...) como o respeito, a civilidade, é um fator muito importante, além da educação básica mesmo, né ?" , embora o ensino mais acadêmico também seja

Paidéia, FFCLRP-USP, Rib. Preto, Fev/Ago 96. 
enfatizado. É interessante notar ainda seu comentário sobre as dificuldades da escola pública, trazendo um discurso repleto de críticas aos professores "que se perderam", ao planejamento que não há, à rotatividade e desinteresse dos profissionais da educação.

\section{DISCUSSÃO}

Os dados desse estudo deixam claro que a importância da escolarização está presente desde a infância dos pais, apenas hoje ela parece ter sofrido uma expansão. A geração mais velha estava atenta, incentivava, cobrava, independentemente de qual fosse o seu nível educacional, enfatizando sempre que "diplomas" poderiam oferecer um futuro mais promissor aos filhos.

Isto se reflete na maneira de pensar e agir dos pais na atualidade, em que a avaliação de seu processo de escolarização é muito boa, e falam da relação entre o progresso no campo profissional e a presença de diplomas, mesmo que estes não se refiram diretamente a seu trabalho atual, mas como um "abrir" possibilidades que aumenta a chance de sucesso em diferentes campos.

Dados de alguns estudos mostram que o valor atribuído à escola, em relação à ascensão social, não acontece apenas em camadas médias, em que o nível educacional alcançado tende a ser maior. Tfouni, Romanelli, Alvares e Garcia (1993) mostram que esta representação também é feita por adultos alfabetizados e analfabetos, pondo às claras uma representação idealizada da instituição escolar.

As consequiências e a exacerbação dessas concepções aparecem de diferentes maneiras na educação dos filhos: a busca de boas escolas; o auxilio às crianças em suas tarefas escolares; valorizando o processo educacional, que provavelmente desembocará em um curso universitário; o propiciar cursos extras que visam um melhor desenvolvimento das crianças e possibilidades de competição mais tarde no mundo do trabalho.

É inegável também que se acentua cada vez mais a idéia de que a criança "precisa" ir cedo para o ambiente coletivo e que, de preferência este lhe dê condições de desenvolver habilidades várias - das sociais às acadêmicas.

Pode-se discutir essa escolarização precoce para muitas das crianças, quer ela se deva ao trabalho da mãe fora de casa, que acaba não tendo pessoas que inspirem confiança no cuidado dos filhos, quer pela necessidade de interação com outros de mesma idade. Estes resultados estão de acordo com a literatura que aponta esta tendência em outros países e no Brasil. Embora existam controvérsias quanto aos aspectos positivos e negativos destes cuidados diários 
sendo realizados por pessoas estranhas à família, cabe o questionamento do quanto a família tem perdido sua função básica de socialização primária ao delegá-la a outras instituições (Sommer \& Langsted, 1994).

Entra-se então no campo dos confrontos entre Família e Escola. A primeira lançando um conjunto de expectativas (às vezes pouco definidas e até incoerentes) que espera serem realizadas pela segunda, que por sua vez se estruturou tendo por base a adoção de uma ou outra concepção teórica sobre Educação Infantil e necessita adequar objetivos gerais, específicos, conteúdo programático a habilidades dos profissionais disponíveis no mercado de trabalho às características da clientela e de seus pais.

Como consequiência, observa-se a crítica òra mais exacerbada, ora mais amena, que parte dos dois lados. A Família questiona atitudes e procedimentos da Escola e esta (se indagada como o foram os pais nesse estudo) devolve, apontando as minúcias das inadequações parentais no trato com seus filhos. Eis aí amplamente semeada a insatisfação.

Pode-se em outros termos dizer que os pais vêm atribuindo à escola maiores responsabilidades e deveres, pois, segundo eles, ela deveria realizar desde a alfabetização até a formação de atitudes de ordem moral e social, o que caracteriza uma elevada expectativa. Para responder a ela os pais colocam suas crianças em escolas particulares, escolhidas em função das características especiais que possuem, e que, na sua visão, não estão presentes na Escola Pública. Esta é considerada como "decadentes" se comparada àquela de sua época de escolarização primária, quando segundo eles, os profissionais ligados à educação eram valorizados socialmente e podiam se dedicar plenamente à tarefa de ensinar.

No entanto, nem mesmo as instituições particulares satisfazem aos pais totalmente. E o círculo se repete. A busca pelas atividades complementares mostra que eles percebem nos filhos necessidades que não são contempladas na escola, e às vezes nem em casa, como a possibilidade de descarregar energias, aprisionadas muitas vezes no pouco espaço para brincar e se exercitar espontaneamente.

No meio fica a criança e a sua infância, ou o que a sociedade atual define e delimita como sendo o esperado para um desenvolvimento saudável e promissor nessa etapa da vida. Isto implica em poder competir em pé de igualdade com os outros e para tal estar desde os primeiros anos submetida aos ditames do mundo adulto no que tange à ocupação do tempo ao longo do dia, ao aproveitamento de todas as oportunidades para desenvolver habilidades à utilidade das atividades a que se dedica.

Este quadro remete diretamente às idéias de Postman (1982) de que a

Paidéia, FFCLRP-USP, Rib. Preto, Fev/Ago 96. 
Infância como nós a conhecemos está desaparecendo e uma nova visão mais utilitária desse período da vida vem surgindo (Biasoli-Alves, 1995), acentuandose a preocupação com o vir-a-ser das gerações mais novas.

\section{REFERÊNCIAS BIBLIOGRÁFICAS}

BIASOLI-ALVES, Z.M.M.. (1995) Família - Socialização - Desenvolvimento. Ribeirão Preto, FFCLRP - USP, ( Tese de Livre Docência)

BIASOLI-ALVES, Z.M.M. e DIAS-DA-SILVA, M.H.G.F. (1992) Análise qualitativa de dados de entrevista, uma proposta. Paidéia, Ribeirão Preto, v.2, p. 61-69, Fev/Jul.

CARDOSO, B (1990) O cotidiano do professor: a construção de uma prática. In: França, GW (coord) Recursos humanos para alfabetização. São Paulo, FDE, p 61-66 (Série Idéias, $n^{\circ} 3$ )

DIAS-DA-SILVA, M.H.G.F. (1986)A educação dos filhos pequenos nos últimos 50 anos: a busca do melhor? São Paulo, IPUSP, (Dissertação de Mestrado)

DI CIOMMO, R.C. Mães trabalhadoras e cuidados maternos substitutivos. In: Nas trilhas da pesquisa. Araraquara, Instituto de Letras, Ciências Sociais e Educação- UNESP

FREITAS, SS, SISTER, BM (1984) Os perigos da muita psicologia na educação dos filhos. Psicologia Atual, 38, mai/jun, p 27-30

FUSARI, JC (1990) Tendências históricas do Treinamento em Educação. In: França, GW (coord) Recursos humanos para alfabetização. São Paulo, FDE, p 13-27 (Série Idéias, $n^{\circ}$ 3)

KLEIMAN, AB (1993) Exclusão social e alfabetização. Temas em Psicologia, $n^{\circ} 3$, p 97-107

PENIN, STS (1990) Estratégias de Desenvolvimento de Pessoal no Interior da Escola. In: FRANÇA, GW (coord) Recursos humanos para alfabetização. São Paulo, FDE, p 49- 52 (Série Idéias, n 3) 
POSTMAN, N. (1982) The disappearance of childhood. New York, Dell Publishing

SOMMER, D, LANGSTED, O. (1994) Modern childhood: crises and disintegration, or a new quality of life ? Childhood, v. 2, p. 129-144

TFOUNI, LM, ROMANELLI, G, ALVARES, AM, GARCIA, RMS (1993) Afinal, para que serve a escola? Representação feita por adultos alfabetizados e analfabetos. Paidéia, $\mathrm{n}^{\circ} 4$

\section{ANEXO}

\section{Escola na infância dos pais}

Idade de início seqüência e término: Com quantos entrou na escola? Aconteceram "bombas" no meio do caminho ? Até quando estudou ? Por quê?

Incentivo ao estudo e tarefas: Havia incentivo para que você estudasse? De quem ? Como era isto de escola, tarefa, na sua casa ? Alguém ajudava ? Por quê?

Qutras atividades: Você fez algum tipo de curso (natação, piano, balé)?

Avaliação: Avalie para mim como foi a escola para você.

\section{Escola na infância dos filhos}

Idade de início: Com quantos o N. foi para a escola ? Por que esta idade?

Incentivo ao estudo e tarefas: Você o incentiva a estudar? Como é isso de escola, tarefa, na sua casa ? Alguém ajuda? Quem?

Outras atividades: $\mathrm{O}$ N. faz outros tipos de cursos (inglês, natação, judô, balé, etc )? Qual o motivo ? Acha importante esses tipos de cursos ?

Papel da escola: O que você espera da escola ?Que papel ela deveria cumprir? 


\begin{abstract}
:
Presently it is common to find someone discussing the School, the changes she is undergoing and the difficulties she is facing. The objectives of this study are to analyse data that describe the school process in the last four decades and to make comparisons identifying the possible variables that can be associated with the changes observed.
\end{abstract}

Key words: School, childrearing practices, family

Palavras Chave: escolarização, práticas educativas, educação de crianças, família. 